\title{
Unmet needs for assistance with activities of daily living among elderly in rural and urban areas in Kwara State Central Senatorial District, Nigeria
}

\author{
Fasiku $\mathrm{MM}^{1}$, Durowade $\mathrm{KA}^{2}$, Bojuwoye $\mathrm{MO}^{3}$, Ahmed $\mathrm{A}^{1}$, Osinubi $\mathrm{MO}^{1}$, Musa $\mathrm{Ol}^{4}$, \\ Osagbemi GK ${ }^{4}$, Akande $\mathrm{TM}^{4}$ \\ ${ }^{1}$ Department of Community Medicine and Primary Care, Federal Medical Centre, Abeokuta \\ ${ }^{2}$ Department of Community Medicine, Federal Teaching Hospital, Ido-Ekiti, and Afe Babalola University, \\ Ado-Ekiti, Ekiti State \\ ${ }^{3}$ Department of Medicine, University of Ilorin, Ilorin, Kwara State \\ ${ }^{4}$ Department of Epidemiology and Community Health, University of Ilorin, Ilorin, Kwara State
}

Submitted: $30^{\text {th }}$ June 2021

Accepted: $29^{\text {th }}$ July 2021

Published: $30^{\text {th }}$ December 2021

\begin{abstract}
Objective: The elderly usually require assistance and sometimes have unmet needs for assistance with activities of daily living. This study assessed the unmet needs for assistance with activities of daily living among the elderly in rural and urban areas in Kwara Central Senatorial District, Nigeria.

Methods: Cross-sectional data were collected using pre-tested semi-structured interviewer-administered questionnaires from 300 elderly using the multistage sampling technique. The Statistical Package for Social Sciences 20 was used to analyze data, and the level of significance was predetermined at a $p$-value less than 0.05 .

Results: Overall, $60 \%$ of the elderly in the urban than rural group $(46 \%)$ had unmet needs for assistance with activities of daily living. The prevalence of unmet needs for assistance with basic activities of daily living in the rural areas ranged from $0.0 \%$ (eating) to $70.8 \%$ (bathing) and $0.0 \%$ (eating) to $68.8 \%$ (transferring) in the urban areas. The prevalence of unmet needs for instrumental activities of daily living ranged from $16.7 \%$ (handling finances) to $59.3 \%$ (cooking) for those in the rural areas. However, the range was from $33.3 \%$ (transportation) to $75.0 \%$ (taking medications) in the urban areas. The urban respondents had higher unmet needs for assistance with telephone use than rural respondents. $\left(p=0.004^{*}\right)$.

Conclusion: The elderly in the urban areas had a higher prevalence of unmet needs for assistance with activities of daily living. The government must address the needs of the elderly through a policy to prevent unmet needs for assistance with activities of daily living.
\end{abstract}

Keywords - Elderly, Unmet needs for assistance, Activities of daily living, rural and urban communities

\section{Plain English Summary}

This study assessed the elderly in rural and urban areas in Kwara State Central Senatorial District, Nigeria, who had unmet needs for assistance (inadequate or absences of needed assistance) to perform their activities of daily living (ADL). The findings revealed that a higher proportion of the elderly in the urban compared to the rural areas had unmet needs for assistance with ADL. In the rural and urban areas, there were also differences in the unmet needs for assistance as regards the selfmaintenance skills, which include eating, bathing, dressing, toileting, transferring, and also complex activities, which permit one to manage one's affairs independently, such as shopping, taking medicines, using the phone, using public transportation and managing finances. 


\section{Background}

The essential self-care tasks that a person is usually expected to engage in on a daily or regular basis is known as "Activities of daily living" (ADL). It can be divided into "Basic activities of daily living" (BADL) and "Instrumental activities of daily living" (IADL). BADL includes self-maintenance skills or a set of common, everyday tasks, performance of which is required for personal self-care and independent living. Examples of these tasks include eating, bathing, dressing, toileting, and transferring (i.e., getting in and out of a bed or chair). "Instrumental activities of daily living" (IADLs) refer to more complex activities that permit one to manage one's affairs independently, such as shopping, taking medicines, using the phone, using public transportation, and managing finances $(1,2)$. ADLs are important because the accumulation of these activities can significantly reduce the time the elderly person spends being sedentary (3).

The United Nations defined the elderly as persons who are at least 60years of age (4). This is the age being adopted too, for the elderly in Nigeria since most working-class people retire at this age. The elderly have varying degrees of disabilities depending on several factors which may necessitate the need for personal assistance to perform ADL. It is increasingly becoming difficult for the elderly to have personal assistance for ADLs due to the breakdown in the extended family support in Nigeria and many other African countries $(5,6)$. There have been unmet needs with regards to assisting the elderly in performing $\operatorname{ADLs}(7,8)$. In Nigeria, it was found that the prevalence of physical disability for people aged 60 years and above was $15.7 \%$ (9). However, whether or not the needs were met was not indicated in the study. Another study in Nigeria among the elderly found that $19.8 \%$ of disabled elderly persons had an unmet need for assistance BADL or IADL (10). Preventing elderly people from becoming limited in performing activities of daily living (ADL) is also an important health objective for maintaining their quality of life. The prevalence of physical disability in elderly persons with functional limitations is, therefore, important for policy development on the care of the elderly. In contrast to the developed nations most developing nations, especially those in sub-Sahara Africa, there is a lack of reliable data to formulate policy on aging despite the increasing populations of their elderly persons $(11,12)$. Elderly people's ability to function independently is therefore important, as physical disability and functional limitation have profound public health implications especially increased utilization of health care and a need for supportive services and long-term care (13). This study, therefore, assessed the unmet needs for assistance with activities of daily living among the elderly in rural and urban areas in Kwara State Central Senatorial District, Nigeria.

\section{Methods \\ Description of the Study Area}

Kwara State is one of the 36 states of Nigeria. It has three senatorial districts, namely, Kwara Central Senatorial District, Kwara South Senatorial District, and Kwara North Senatorial District. Kwara Central Senatorial District was the study area, and it is made up of four Local government areas (LGA), namely, Asa, Ilorin East, llorin West, and Ilorin South LGAs.

The elderly constitute about $6 \%$ of the population in Nigeria (14). The projected total population of the elderly 60 years and older based on the 2006 census in the study area is 9,490 .

\section{Study Population}

The study population consisted of the elderly who were 60 years and older (both males and females) in rural and urban areas of Kwara Central Senatorial District.

\section{Inclusion and exclusion criteria}

The elderly (both males and females), in rural and urban communities in Kwara Central Senatorial District who are permanent residents for 6 months and above in the communities The study excluded the elderly who could not communicate through any means, those without sufficient cognitive ability to answer the study questions, and the acutely ill or those who did not cooperate due to ill-health.

\section{Study Design}

The study is a community-based crosssectional analytical study on the unmet needs for assistance with activities of daily living among the elderly in rural and urban settings in Kwara Central Senatorial District in Nigeria.

\section{Sample size determination}

The minimum sample size was determined using the formula for comparison of two proportions (15). After adjusting for $10 \%$ nonresponse, a minimum sample size of 294 was obtained. However, a total of 300 respondents were interviewed (150 each for rural and urban areas).

\section{Sampling technique}

A multistage sampling technique was used for the selection of respondents for this study. 
Kwara Central Senatorial District has 4 LGAs. Two LGAs were selected; Asa a rural LGA and llorin East LGA an urban LGA through simple random sampling by balloting. Two wards were randomly selected by simple random sampling by balloting from each of the urban and rural LGAs selected. The list of the communities in the 4 wards selected was generated. Two communities were selected by the use of the table of random numbers from each of the selected wards, giving 4 urban and 4 rural communities (A total of 8 communities). Then proportionate allocation was again used to allocate questionnaires to each of the selected communities based on their populations. A systematic sampling technique was used to select the households to be sampled using the sampling frame and where there was more than one eligible elderly person, a simple random sampling technique by balloting was used to select one eligible elderly. When there was no elderly person in the household, the next household was visited until an eligible respondent was found, but still maintained the sampling interval.

\section{Data Collection}

The data was obtained using a pre-tested, semi-structured interviewer-administered questionnaire to elicit information from eligible respondents. The questionnaire was developed and adapted from BADL and IADL tools and a review of relevant research work on the topic (1, 16). Validity of the content was achieved through consultation of relevant literature on unmet needs for assistance with Activities of Daily Living among the elderly.

Data Management

The data obtained were entered into a personal computer after being manually checked for possible errors. Analysis was done using Statistical Package for Social Sciences (SPSS) version 20.0. Descriptive statistics were used to examine the prevalence of those indicating difficulty in performing ADLs and IADLs. Then, for those indicating difficulty with at least one of the six ADLs (bathing, dressing, toileting, transferring, walking, and eating) or eight IADLs (Using the telephone, shopping, cooking, housework, laundry, transportation, taking medication, and finance management), the prevalence of those indicating no need, met need, and unmet need by each activity was determined. Thereafter, the unmet need for assistance with the activity of daily living among those with a need for assistance was determined. The analytic sample to examine assistance need status (no need, met need, and unmet need) was restricted to those who reported one or more ADL or IADL difficulties.

The Chi-square test was used to determine the statistical significance of observed differences in cross-tabulated categorical variables. The frequencies and proportions were presented in tables. A $p$-value of less than 0.05 was considered significant.

\section{Results}

The mean age of respondents in the rural area was approximately $76.00 \pm 12.00$ years compared to the urban area that was approximately $74 \pm 10$ years. The proportion of the female respondents was higher than males in both rural and urban areas, $(96 ; 64 \%$ ) and $(84 ; 56 \%)$ respectively. The differences in the religion $(<0.001)$, type of family $(<0.001)$, educational status $(<0.001)$, and employment status $(0.001)$ of the respondents in the rural and urban areas were statistically significant (Table 1).

\begin{tabular}{|c|c|c|c|c|}
\hline Variable & $\begin{array}{l}\text { Rural } \\
\text { n (\%) }\end{array}$ & $\begin{array}{l}\text { Urban } \\
\text { n (\%) }\end{array}$ & $x^{2}$ & $p$-value \\
\hline \multicolumn{5}{|c|}{ Age group (years) } \\
\hline $60-69$ & $51(34.0)$ & $62(41.3)$ & 7.383 & 0.061 \\
\hline $70-79$ & $39(26.0)$ & $50(33.3)$ & & \\
\hline $80-89$ & $34(22.7)$ & $22(14.7)$ & & \\
\hline$\geq 90$ & $26(17.3)$ & $16(10.7)$ & & \\
\hline Mean \pm SD & $76.04 \pm 11.587$ & $73.83 \pm 10.44$ & $1.738^{\mathrm{a}}$ & 0.083 \\
\hline \multicolumn{5}{|l|}{ Sex } \\
\hline Male & $54(36.0)$ & $66(44.0)$ & 2.000 & 0.157 \\
\hline Female & $96(64.0)$ & $84(56.0)$ & & \\
\hline \multicolumn{5}{|l|}{ Religion } \\
\hline Christianity & $5(3.3)$ & $71(47.3)$ & 76.762 & $<0.001^{*}$ \\
\hline Islam & $145(96.7)$ & $79(52.7)$ & & \\
\hline
\end{tabular}




\begin{tabular}{lllll}
\hline Marital Status & & & & \\
$\quad$ Married & $75(50.0)$ & $89(59.3)$ & 2.636 & 0.104 \\
Widowed & $75(50.0)$ & $61(40.7)$ & & \\
$\begin{array}{l}\text { Type of Family } \\
\quad \text { Monogamy }\end{array}$ & $55(36.7)$ & $93(62.0)$ & 19.257 & $<0.001^{*}$ \\
$\quad \begin{array}{l}\text { Polygamy } \\
\text { Educational Level }\end{array}$ & $95(63.3)$ & $57(38.0)$ & & \\
No formal education & $133(88.7)$ & $71(47.3)$ & 61.310 & $<0.001^{*}$ \\
$\quad \begin{array}{l}\text { Primary education } \\
\text { Secondary education }\end{array}$ & $11(7.3)$ & $31(20.7)$ & & \\
Tertiary education & $4(2.7)$ & $9(6.0)$ & & \\
Employment status & & $39(26.0)$ & & \\
$\quad$ Employed & $108(72.0)$ & $81(54.0)$ & 10.425 & $0.001^{*}$ \\
Unemployed & $42(28.0)$ & $69(46.0)$ & & \\
\hline$X^{2}:$ Chi square test, ${ }^{*}: p$ value $<0.05$ (statistically significant), a: student's t test
\end{tabular}

The proportion of those that had difficulty performing one or more BADL/IADL, in the rural area was higher $87(58.0 \%)$ than those respondents from the urban area $70(46.7 \%)$. However, the number of respondents with unmet needs for assistance with one or more BADL/IADL in the rural area $40(46.0 \%)$ was slightly lower than in the urban area $42(60.0 \%)$ (Table2).

Table 2: Respondents with difficulty performing and unmet needs for assistance with at least one activity of daily living

\begin{tabular}{lllll}
\hline Variable & $\begin{array}{l}\text { Rural } \\
\mathbf{n}(\%)\end{array}$ & $\begin{array}{l}\text { Urban } \\
\mathbf{n}(\%)\end{array}$ & $\mathbf{X}^{\mathbf{2}}$ & $\boldsymbol{p}$-value \\
\hline $\begin{array}{l}\text { Difficulty in performing at least } \\
\text { one activity }\end{array}$ & $\mathbf{n = 1 5 0}$ & $\mathbf{n = 1 5 0}$ & & \\
$\quad$ Yes & $87(58.0)$ & $70(46.7)$ & 3.862 & $0.049^{*}$ \\
$\quad$ None & $63(42.0)$ & $80(53.3)$ & & \\
Unmet needs for assistance & $\mathbf{n = 8 7}$ & $\mathbf{n = 7 0}$ & & \\
No & $47(54.0)$ & $28(40.0)$ & 3.057 & 0.080 \\
Yes & $40(46.0)$ & $42(60.0)$ & & \\
\hline
\end{tabular}

Estimates of unmet need for BADL ranged from $0.0 \%$ for eating to $70.8 \%$ for bathing for those in the rural area (Table 3 ) and the estimates of unmet need for BADL ranged from $0.0 \%$ for eating to $68.8 \%$ for transferring for those in the urban area (Table 4). The estimates of unmet need for IADL ranged from $16.0 \%$ for handling finances to $59.3 \%$ for cooking for those in the rural area (Table 3 ) and the estimates of unmet need for IADL ranged from $33.3 \%$ for transportation to $75.0 \%$ for taking medications for those in the urban area (Table 4).

Table 3: Need and Unmet Assistance Need with BADL/IADLs in the rural group ( $n=87)$

\begin{tabular}{lllll}
\hline & $\begin{array}{l}\text { Difficulty } \\
\text { performing }\end{array}$ & \multicolumn{2}{c}{ Assistance need status } \\
Variable & $\mathbf{n}(\%)$ & $\begin{array}{l}\text { No need } \\
\mathbf{n}(\%)\end{array}$ & $\begin{array}{l}\text { Unmet need } \\
\mathbf{n}(\%)\end{array}$ & $\begin{array}{l}\text { Met need } \\
\mathbf{n}(\%)\end{array}$ \\
\hline BADLs & & & & \\
Bathing & $24(16.0)$ & $2(8.3)$ & $17(70.8)$ & $5(20.8)$ \\
Dressing & $13(8.7)$ & $4(30.8)$ & $7(53.8)$ & $2(15.4)$ \\
Toileting & $8(5.3)$ & $3(37.5)$ & $4(50.0)$ & $1(12.5)$ \\
Transferring & $15(10.0)$ & $3(20.0)$ & $10(66.7)$ & $2(13.3)$ \\
Walking & $12(8.0)$ & $8(66.7)$ & $2(16.7)$ & $2(16.7)$ \\
Eating & $1(0.7)$ & $1(100.0)$ & $(0.0)$ & $(0.0)$ \\
IADLs & & & & \\
Using telephone & $52(34.7)$ & $8(15.4)$ & $14(26.9)$ & $30(57.7)$ \\
Shopping & $24(16.0)$ & $3(12.5)$ & $14(58.3)$ & $7(29.2)$ \\
\hline
\end{tabular}




\begin{tabular}{lllll}
\hline Cooking & $27(18.0)$ & $2(7.4)$ & $16(59.3)$ & $9(33.3)$ \\
Housework & $35(23.3)$ & $1(2.9)$ & $16(45.7)$ & $18(51.4)$ \\
Laundry & $33(22.0)$ & $1(3.0)$ & $16(48.5)$ & $16(48.5)$ \\
Transportation & $30(20.0)$ & $9(30.0)$ & $10(33.3)$ & $11(36.7)$ \\
Taking medication & $15(10.0)$ & $6(40.0)$ & $6(40.0)$ & $3(20.0)$ \\
Finance management & $12(8.0)$ & $6(50.0)$ & $2(16.7)$ & $4(33.3)$ \\
\hline \multicolumn{5}{c}{${ }^{a}$ Reported difficulty. }
\end{tabular}

${ }^{\mathrm{b}}$ The denominator represents persons with a stated difficulty in each ADL or IADLs.

Table 4: Need and Unmet Assistance Need with BADL/IADLs in the urban group $(n=70)$ Difficulty performing $^{\text {a }}$ Assistance need status ${ }^{b}$

\begin{tabular}{lllll} 
ADL/IADLs & $\mathbf{n}(\%)$ & $\begin{array}{l}\text { No need } \\
\mathbf{n}(\%)\end{array}$ & $\begin{array}{l}\text { Unmet need } \\
\mathbf{n}(\%)\end{array}$ & $\begin{array}{l}\text { Met need } \\
\mathbf{n}(\%)\end{array}$ \\
\hline ADL & & & & \\
Bathing & $6(4.0)$ & $1(16.7)$ & $4(66.7)$ & $1(16.7)$ \\
Dressing & $3(2.0)$ & $1(33.3)$ & $2(66.7)$ & $0(0)$ \\
Toileting & $2(1.3)$ & $1(50.0)$ & $1(50.0)$ & $0(0)$ \\
Transferring & $16(10.7)$ & $2(12.5)$ & $11(68.8)$ & $3(18.8)$ \\
Walking & $11(7.3)$ & $3(27.3)$ & $5(45.5)$ & $3(27.3)$ \\
Eating & $0(0.0)$ & $0(0.0)$ & $0(0.0)$ & $0(0.0)$ \\
IADLs & & & & \\
Using telephone & $29(19.3)$ & $2(6.9)$ & $18(62.1)$ & $9(31.0)$ \\
Shopping & $33(22.0)$ & $3(9.1)$ & $15(45.5)$ & $15(45.5)$ \\
Cooking & $38(25.3)$ & $3(7.9)$ & $20(52.9)$ & $15(39.5)$ \\
Housework & $43(28.7)$ & $3(7.0)$ & $23(53.5)$ & $17(39.5)$ \\
Laundry & $43(28.7)$ & $3(7.0)$ & $23(53.5)$ & $17(39.5)$ \\
Transportation & $24(16.0)$ & $7(29.2)$ & $8(33.3)$ & $9(37.5)$ \\
Taking medication & $8(5.3)$ & $1(12.5)$ & $6(75.0)$ & $1(12.5)$ \\
Finances & $10(6.7)$ & $3(30.0)$ & $5(50.0)$ & $2(20.0)$ \\
\hline
\end{tabular}

${ }^{a}$ Reported difficulty.

${ }^{\mathrm{b}}$ The denominator represents persons with a stated difficulty in each ADL or IADLs.

Differences in those with unmet needs among those in the rural (Table 5) and urban areas (Table 6) were not statistically significant for all the activities for the BADL. However, for the IADL, the differences in those with unmet needs were not statistically significant for all the activities except telephone use, where the proportion of unmet need among the urban area respondents was higher than that of rural areas, and this difference was statistically significant $\left(p=0.004^{*}\right)($ Table 6$)$.

Table 5: Unmet needs for assistance with basic activities of daily living among rural and urban respondents with difficulty performing activities

\begin{tabular}{|c|c|c|c|c|}
\hline ADL & $\begin{array}{l}\text { Rural } \\
\text { n (\%) }\end{array}$ & $\begin{array}{l}\text { Urban } \\
\text { n (\%) }\end{array}$ & $x^{2}$ & $p$-value \\
\hline \multicolumn{5}{|l|}{ Bath } \\
\hline Unmet need & $17(77.3)$ & $4(80.0)$ & $0.215^{Y}$ & 0.642 \\
\hline Met need & $5(22.5)$ & $1(20.0)$ & & \\
\hline \multicolumn{5}{|l|}{ Dressing } \\
\hline Unmet need & $7(77.8)$ & $2(100.0)$ & $0.076^{Y}$ & 0.782 \\
\hline Met need & $2(22.2)$ & $0(0.0)$ & & \\
\hline \multicolumn{5}{|l|}{ Toileting } \\
\hline Unmet need & $4(80.0)$ & $1(100.0)$ & $0.960^{Y}$ & 0.327 \\
\hline Met need & $1(20.0)$ & $0(0.0)$ & & \\
\hline \multicolumn{5}{|l|}{ Transferring from chair/bed } \\
\hline Unmet need & $10(83.3)$ & $11(78.6)$ & $0.037^{Y}$ & 0.847 \\
\hline
\end{tabular}




\begin{tabular}{lllll}
\hline Met need & $2(16.7)$ & $3(21.4)$ & & \\
Walking & & & \\
$\quad$ Unmet need & $2(50.0)$ & $5(62.5)$ & $0.043^{\curlyvee}$ & 0.835 \\
Met need & $2(50.0)$ & $3(37.5)$ & & \\
\hline
\end{tabular}

$\mathrm{X}^{2}$ : Chi square test, ${ }^{Y}$ : Yates correction, $p$ value, ${ }^{*}: p$ value $<0.05$ (statistically significant)

The denominator is persons with need (either met need or unmet need) for ADL assistance.

Table 6: Unmet needs for assistance with instrumental activities of daily living among rural and urban respondents with needs for assistance

\begin{tabular}{|c|c|c|c|c|}
\hline IADLs & $\begin{array}{l}\text { Rural } \\
\text { n (\%) }\end{array}$ & $\begin{array}{l}\text { Urban } \\
\mathrm{n}(\%)\end{array}$ & $x^{2}$ & $p$-value \\
\hline \multicolumn{5}{|l|}{ Telephone } \\
\hline Unmet need & $14(31.8)$ & $18(66.7)$ & \multirow[t]{2}{*}{8.208} & \multirow[t]{2}{*}{$0.004^{*}$} \\
\hline Met need & $30(68.2)$ & $9(33.3)$ & & \\
\hline \multicolumn{5}{|l|}{ Shopping } \\
\hline Unmet need & $14(66.7)$ & $15(50.0)$ & \multirow[t]{2}{*}{1.399} & \multirow[t]{2}{*}{0.237} \\
\hline Met need & $7(33.3)$ & $15(50.0)$ & & \\
\hline \multicolumn{5}{|l|}{ Cooking help } \\
\hline Unmet need & $16(64.0)$ & $20(57.1)$ & \multirow[t]{2}{*}{0.286} & \multirow[t]{2}{*}{0.593} \\
\hline Met need & $9(36.0)$ & $15(42.9)$ & & \\
\hline \multicolumn{5}{|c|}{ Doing housework } \\
\hline Unmet need & $16(47.1)$ & $23(57.5)$ & \multirow[t]{2}{*}{0.804} & \multirow[t]{2}{*}{0.370} \\
\hline Met need & $18(52.9)$ & $17(42.5)$ & & \\
\hline \multicolumn{5}{|l|}{ Laundry help } \\
\hline Unmet need & $16(50.0)$ & $23(57.5)$ & \multirow[t]{3}{*}{0.403} & \multirow[t]{2}{*}{0.526} \\
\hline Met need & $16(50.0)$ & $17(42.5)$ & & \\
\hline \multicolumn{4}{|c|}{ Transportation help } & \\
\hline Unmet need & $10(47.6)$ & $8(47.1)$ & \multirow[t]{3}{*}{0.001} & \multirow[t]{2}{*}{0.973} \\
\hline Met need & $11(52.4)$ & $9(52.9)$ & & \\
\hline \multicolumn{4}{|c|}{ Taking medication help } & \\
\hline Unmet need & $6(66.7)$ & $6(85.7)$ & \multirow[t]{2}{*}{$0.762^{Y}$} & \multirow[t]{2}{*}{0.770} \\
\hline Met need & $3(33.3)$ & $1(14.3)$ & & \\
\hline \multicolumn{5}{|c|}{ Handling finances help } \\
\hline Unmet need & $2(33.3)$ & $5(71.4)$ & \multirow{2}{*}{$0.665^{Y}$} & \multirow{2}{*}{0.414} \\
\hline Met need & $4(66.7)$ & $2(28.6)$ & & \\
\hline
\end{tabular}

\section{Discussion}

This study found differences between the rural and urban elderly in terms of unmet needs for assistance with ADL. The prevalence of unmet needs for assistance with ADL was higher in the urban than the rural area. Studies in America and India also showed similar findings $(17,18)$. Those in the rural area had a lower proportion of unmet needs for assistance with bathing and dressing than those in the urban group who had greater unmet needs for assistance with bathing and dressing. It could be attributed to the communal way of life in the rural areas where anyone could be beckoned upon for assistance which may not be available to those in the urban areas where people usually live a cosmopolitan way of life. These findings were different from those in other studies conducted in America, which had a lower proportion of those unmet needs for bathing and dressing (7, 18). This could be attributed to the availability of different options of care for the elderly in such places.

Of all the elderly studied, only one had unmet needs for assistance with toileting, and this elderly was an urban dweller. This proportion of unmet need for assistance with toileting was similar to other studies $(17,18)$. About one-third of the rural respondents had unmet needs for telephone use, while two-thirds of those respondents in the urban area had an unmet need for assistance with telephone use. The higher prevalence in the urban than the rural area could be as a result of the elderly in the rural area getting help from neighbors. However, due to the way the urban area is structured it is oftentimes difficult to have a communal way of living. These unmet needs for assistance with telephone use among the rural and urban areas were higher than that reported in a study conducted in America which reported slightly above one-tenth of those studied (18). 
The unmet need for assistance with walking was different from other studies conducted (7, 19). The rural than the urban group, had a greater proportion of those with unmet needs for assistance with shopping. These findings contrast with findings from a study among American Indians where a smaller proportion had an unmet need for assistance with shopping (18). This could be a result of the availability of different options for the care of the elderly in America.

The greater proportion of unmet needs for assistance with cooking in the rural than in urban group may be as a result of the presence of appliances that could help with cooking such as the use of gas or electronic stoves, microwave machines, while such may not be available in the rural area. This also applies to performing laundry activity which could be better handled with appliances like washing machines, thereby allowing those in the urban area to better manage their laundry than the rural area where such is not available. This is different from studies conducted in America and Vietnam that had lower unmet needs $(18,20)$.

Both the rural and the urban areas had a similar proportion of unmet needs as regards transportation. The study conducted among American Indians revealed a lower proportion of unmet needs for assistance with transportation (18). Considering responsibility for taking own medications and handling finances, a greater proportion of the elderly in the urban than the rural area, had unmet needs for assistance with these. This could be because more respondents in urban than rural areas lived alone as found out by this study. The proportion of respondents with unmet needs for taking medication in the rural and urban areas was higher than those reported by studies in both America and Malaysia $(18,21)$.

\section{Limitations of the study}

There is a need to exercise caution in making direct comparisons with other studies because there were differences in measurement and study inclusion criteria. There is a dearth of studies on unmet needs for assistance with $A D L$, especially in the study area.

\section{Conclusion}

In this study, unmet needs for assistance with performing both BADL and IADL among the elderly were generally high but higher in the urban areas, and there were differences in both the rural and urban areas. It will be worthwhile to conduct National surveys to determine the unmet needs for assistance with activities of daily living in the whole country since this was conducted in a senatorial district in one of the states of the country. The results of such findings can assist policy-makers to address the unmet needs for assistance with BADL/IAD through the development of programs such as optimal social security systems, elderly people's homes, etc, that will address the unmet needs for assistance with activities of daily living for the elderly.

\section{List of abbreviations}

ADL: Activities of Daily Living

BADL: Basic Activities of Daily Living

IADL: Instrumental Activities of Daily Living

LGA: Local Government Area

\section{Declarations}

Ethics approval and consent to participate

Ethical clearance to conduct the study was obtained from the Ethical Review Committee of the University of Ilorin Teaching Hospital with approval number ERC PAN/2016/10/1606. Written informed consent was obtained from respondents. Participation was voluntary. All information obtained was treated with the utmost confidentiality.

\section{Consent for publication}

The authors hereby give consent for the publication of our work under the creative commons CC Attribution-Non-commercial 4.0 license.

\section{Competing interests}

None to declare

\section{Funding}

No funding was received for the conduct of this research.

\section{Authors' contributions}

Conceptualization- FMM, ATM; Designed the study- FMM, ATM, MOI, OGK; Data collection and analysis- FMM, DKA, BMO, AA, OMO; Drafting the manuscript-FMM, MOI, DKA; Proof-read manuscript-MOI, ATM, BMO, DKA, AA; Approval of the final draft- All the authors.

\section{Acknowledgments}

We appreciate the assistance of Dr. Afolayan $\mathrm{AM}$ and Prof Abdulraheem IS.

\section{References}

1. Lawton MP, Brody EM. Assessment of older people: self-maintaining and instrumental activities of daily living. The gerontologist. 1969;9(3_Part_1):179-86.

https://doi.org/10.1093/geront/9.3 part 1.1 $\underline{79}$

2. Gibson M, Verma S. Just Getting by: Unmet Need for Personal Assistance Services 
Among Persons 50 Or Older with Disabilities. Washington, D.C: Public Policy Institute. 2006;

3. Guidelines on physical activity for older people (aged 65years and over). New Zealand: Ministry of Health New Zealand. 2013.

4. Dugarova E. Ageing, older persons and the 2030 agenda for sustainable development. United Nations Development Programme; New York. 2017. https://doi.org/10.18356/1af7e1b7-en

5. Wiener JM, Hanley RJ, Clark R, Van Nostrand JF. Measuring the activities of daily living: Comparisons across national surveys. Journal of gerontology. 1990;45(6):S229-37.

https://doi.org/10.1093/geronj/45.6.s229

6. Norburn JE, Bernard S, Konrad T. Self-care and assistance from others in coping with functional status limitations among a national sample of adults. J Gerontol B Psychol Sci Soc Sci. 1995;50:101-9.

7. Desai MM, Lentzner HR, Weeks JD. Unmet need for personal assistance with activities of daily living among older adults. The Gerontologist. $\quad 2001 ; 41(1): 82-8$. https://doi.org/10.1093/geront/41.1.82

8. Andrade TB de, Andrade FB de. Unmet need for assistance with activities of daily life among older adults in Brazil. Revista de saude publica. 2018;52:75. https://doi.org/10.11606/s15188787.2018052000463

9. Abdulraheem IS, Oladipo AR, Amodu M. Prevalence and Correlates of Physical Disability and Functional Limitation among Elderly Rural Population in Nigeria. Journal of Aging Research. 2011; https://doi.org/10.4061/2011/369894

10.Gureje O, Ogunniyi A, Kola L, Afolabi E. Functional Disability among elderly Nigerians: results from the Ibadan Study of Ageing. J Am Geriatr Soc. 2006;54(11):1784-9. https://doi.org/10.1111/j.15325415.2006.00944.x

11. Frenk J, Chen L, Bhutta ZA, Cohen J, Crisp $\mathrm{N}$, Evans $\mathrm{T}$, et al. Health professionals for a new century: transforming education to strengthen health systems in an interdependent world. Lancet. 2010;376(9756):1923-58. https://doi.org/10.1016/s01406736(10)61854-5

12. Balamurugan J, Ramathirtham G. Health problems of Aged People. International Research Journal in social sciences. 2012;2(3):139-50.

13. Fried L, Guralnik J. Disability in older adults: evidence regarding significance, etiology, and risk. J Am Geriatr Soc. 45:92-100. https://doi.org/10.1111/j.15325415.1997.tb00986.x

14.National Population Commission. Population census of the Federal Republic of Nigeria. Preliminary Report. Nigeria: Author and ICF Macro.

15. Taofeek I. Research Methodology and Dissertation writing for Health and Allied Health Professionals. 1st ed. Abuja: Cress Global Link Limited; 2009.

16.Katz S. Assessing self-maintenance: activities of daily living, mobility, and instrumental activities of daily living. Journal of the American Geriatrics Society. 1983;31(12):721-7.

https://doi.org/10.1111/j.1532-

5415.1983.tb03391.x

17. Henning-Smith C, Wu Z, Lahr M. Unmet Need for Personal Care Assistance among Rural and Urban Older Adults. 2019;

18.Schure MB, Conte KP, Goins RT. Unmet Assistance Need Among Older American Indians: The Native Elder Care Study. The Gerontologist. :2014. https://doi.org/10.1093/geront/gnt211

19. Liu Y-H, Chang H-J, Huang C-C. The unmet activities of daily living (ADL) needs of dependent elders and their related factors: an approach from both an individual-and area-level perspective. International Journal of Gerontology. 2012;6(3):163-8. https://doi.org/10.1016/j.ijge.2012.05.009

20. Hoi LV, Thang P, Lindholm L. Elderly care in daily living in rural Vietnam: Need and its socioeconomic determinants. BMC Geriatrics. 2011;11:81. https://doi.org/10.1186/1471-2318-11-81

21. Momtaz YA, Hamid TA, Ibrahim R. Unmet needs among disabled elderly Malaysians. Social Science \& Medicine. 2012;75:85963.

https://doi.org/10.1016/j.socscimed.2012.03 .047 